\title{
Pendampingan Pengembangan Potensi Desa untuk Pemenuhan Gizi Sebagai Pencegahan Stunting Ditengah Pandemik Covid-19 Dalam Ketersediaan Pangan Masyarakat Desa Kawasan Pesisir Kabupaten Pohuwato
}

\author{
Sarson W. Dj. Pomalato', Syamsu Qamar Badu², Mohamad Taufik \\ Zulfikar Sarson ${ }^{3}$ \\ ${ }_{1,2,3}$ Fakultas Matematika dan IImu Pengetahuan Alam Universitas Negeri Gorontalo \\ JI. Prof. Dr. Ing. B.J. Habibie, Kabupaten Bone Bolango. Kode Pos 96119. \\ e-mail: sarson@ung.ac.id
}

\begin{abstract}
Abstrak
Pengabdian ini bertujuan untuk; 1) Mengelola potensi desa; untuk mengoptimalkan potensi sumberdaya manusia; melalui; aksi nyata pemerintah desa dan kerja sama masyarakat untuk mengelola potensi Desa, melalui agenda kegiatan; FGD: Program utama; Optimalisasi Pelayanan Aparat Desa. Materi; Kesehatan dan Kepatuhan Hukum oleh Pemerintah Desa dalam pencegahan dan penanganan Stunting dalam situasi New Normal pasca pandemik Covid-19, melalui Tertib Hukum dalam pelayanan kesehatan masyarakat Pohuwato kawasan wilayah pesisir. Pentingnya kegiatan ini; Untuk mendapatkan penanganan kesehatan yang optimal dan ketertiban serta keterlibatan juga kepatuhan program pemerintah dalam kepatuhan protap kesehatan dan . 2) Pendampingan pelayanan Gizi untuk kesehatan masyarakat. Agenda kegiatan yang kedua untuk mengoptimalkan Pelayanan posyandu Desa/kelurahan/kecamatan, sebagai basis pelayanan kesehatan masyarakat; terutama untuk ibu hamil dan anak balita (kegiatannnya dalam bentuk BimTek dan gerakan aski pelayanan kesehatan untuk ibu hamil dan anak balita, serta donor darah). Pentingnya kegiatan; untuk melayani langsung masyarakat; gerakan aksi pelayanan untuk masyarakat dalam menangani Stunting. 3) BimTek; Sosialisasi Pola Hidup Sehat (PHBS); Patuh Protap Kesehatan; Geraka aksi kegiatan ketiga; Cara Cuci tangan dan Pakai masker; Bagi-bagi masker masyarakat pesisir. 4) Pelatihan menanam tanaman di halaman dan kebun. Aksi kegiatan keempat ini; dilaksankan bersama DPL, Mahasiswa, Aparat Desa dan Pemateri (Agro Teknologi Pertanian). 5) Program Tambahan; Pengolahan Potensi Pertanian, laut dan tambak untuk kawasan wilayah pesisir; Krepek sayur bayam, Penggaraman Ikan Batu dan Naghet Udang. Pelaksana Kegiatan; 1) Perguruan Tinggi (Tim DPL dan Mahasiswa, dan akademisi/Ahli atau pakar dalam keilmuan bidang program kegiatan) 2) Pemerintah Kabupaten/Kecamatan/Desa sebagai Mitra dan 3) keterlibatan seluruh masyarakat Desa. Adapun Hasil dari kegiatan pengabdian ini, (a) Masyrakat mendapatkan pelayanan optimal dari aparat/perangkat Desa. b) Peningkatan kesehatan Stunting c) Peningkatan Kesadaran masyarakat agar tertib dalam Protap kesehatan dalam situasi dan kondisi New Normal Setelah wabah Covid-19 d) Meningkatkan kesejahteraan dan perekonomian serta e) ketrampilan masyarakat dalam memanfaatkan lahan untuk produksi tanaman lokal untuk ketersediaan pangan, f) jika berlebih produksi lokal masyarakat dapat dijual dalam pemenuhan gizi dan obat tradisional untuk pencegahan penyakit masyarakat
\end{abstract}


kawasan wilayah pesisir. Out Put Kegiatan: Grand Design Desa; Model Pengembangan Potensi Desa; Gerakan Aksi Tanggap Kesehatan Bebas Stunting dan Gerakan Tertib Hukum Protap Kesehatan Covid-19, melalui ketahanan pangan masyarakat kawasan wilayah pesisir. Luaran; artikel: Media Cetak/online. YouTube. Seminar Nasional/Internasional. Jurnal Pengabdian dan Buku Panduan sesuai Grand Design Desa

Kata Kunci: Potensi Desa. Cegah Stunting. Pandemik Covid-19. Ketersediaan Pangan. Kawasan Wilayah Pesisir

\begin{abstract}
This service aims to; 1) Managing village potential; to optimize the potential of human resources; through; real actions of the village government and community cooperation to manage the potential of the village, through the activity agenda; FGD: Main program; Optimization of Village Apparatus Services. Material; Health and Legal Compliance by the Village Government in preventing and handling Stunting in the New Normal situation after the Covid-19 pandemic, through Law Order in public health services for the Pohuwato community in the coastal area. The importance of this activity; To obtain optimal health care and order and involvement as well as compliance with government programs in compliance with health and safety protocols. 2) Assistance in nutrition services for public health. The second agenda of activities is to optimize village/kelurahan/sub-district posyandu services, as the basis for public health services; especially for pregnant women and children under five (its activities are in the form of technical guidance and the movement for asking for health services for pregnant women and children under five, as well as blood donation). The importance of the activity; to serve the community directly; service action movement for the community in dealing with stunting. 3) BimTek; Socialization of Healthy Lifestyle (PHBS); Adhere to Health Standards; The third activity action movement; How to wash hands and wear masks; Distribute masks to coastal communities. 4) Training on growing plants in the yard and garden. The action of this fourth activity; carried out with DPL, students, village officials and speakers (Agro Agricultural Technology). 5) Additional Programs; Processing Potential of Agriculture, sea and ponds for coastal areas; Spinach vegetable crackers, Rock Fish Salting and Shrimp Naghet. Event organiser; 1) Universities (DPL Team and Students, and academics/Experts or experts in scientific fields of activity programs) 2) Regency/District/Village Governments as Partners and 3) involvement of the entire Village community. As for the results of this service activity, (a) the community gets optimal service from the village apparatus / apparatus. b) Improved stunting health c) Increased public awareness to be orderly in health protocols in New Normal situations and conditions after the Covid-19 outbreak d) Improve welfare and economy and e) community skills in utilizing land for local crop production for food availability, f) If there is excess local community production, it can be sold to fulfill nutrition and traditional medicine for the prevention of diseases in coastal areas. Out Put Activities: Grand Design Village; Village Potential Development Model; The Stunting-Free Health Response Action Movement and the Covid-19 Health Order Law Movement, through the food security of the people of coastal areas. Outer; article: Print Media/online. YouTube. National/International Seminars. Devotion Journal and Guidebook according to Grand Design Village
\end{abstract}

Kata Kunci: Village Potential. Prevent Stunting. Covid-19 pandemic. Food availability. Coastal Area 
(C) 2021 Sarson W. Dj. Pomalato, Syamsu Qamar Badu, Mohamad Taufik Zulfikar Sarson Under the license CC BY-SA 4.0

Correspondence author: Sarson W. Dj. Pomalato, sarson@ung.ac.id, Gorontalo, and Indonesia

\section{PENDAHULUAN}

Kabupaten Pohuwato merupakan salah satu kabupaten di Provinsi Gorontalo yang terletak dibagian barat dari Provinsi Gorontalo yang terletak antara $0^{\circ} 22^{\prime}-0^{\circ} 57^{\prime}$ Lintang Utara dan 121o 23' - 1220 19' Bujur Timur. Berdasarkan posisi geografisnya, Kabupaten Pohuwato berbatasan dengan Kabupaten Buol (Provinsi Sulawesi Tengah) dan Kecamatan Sumalata (Kabupaten Gorontalo Utara) di sebelah utara, Teluk tomini di sebelah selatan, Kabupaten Parigi Moutong dan Kabupaten Buol (Provinsi Sulawesi Tengah) di sebelah barat, dan Kecamatan Mananggu (Kabupaten Boalemo) di sebelah timur dan memiliki jumlah penduduk sebanyak 146.900 jiwa, dengan kepadatan penduduk Kabupaten Pohuwato mencapai $35 \mathrm{Jiwa} / \mathrm{Km}^{2}$, adapun jumlah penduduk kecamatan Kwandang menurut data yang diperoleh pada tahun 2007 adalah 34.106 jiwa dengan luas wilayah yang mencapai $336.80 \mathrm{~km}^{2}$.

Berdasarkan data dari Dinas Pemberdayaan Masyarakat Desa Kabupaten Pohuwato, wilayah Kabupaten Pohuwato terdiri atas tiga belas (13) kecamatan, yaitu Kecamatan Popayato, Popayato Barat, Popayato Timur, Lemito, Wanggarasi, Marisa, Patilanggio, Buntulia, Duhiadaa, Randangan, Taluditi, Paguat, dan Dengilo dan 104 Desa/Kelurahan dan terbagi dua kecamatan dengan luas wilayah besar, yaitu; Kecamatan Popayato Timur, merupakan kecamatan yang terjarang penduduknya memiliki 12 Jiwa $/ \mathrm{Km}^{2}$ dan Kecamatan Marisa, 
merupakan kecamatan terpadat penduduknya mencapai 607 Jiwa/ $/ \mathrm{Km}^{2}$. Kabupaten Pohuwato menduduki posisi strategis sebagai pusat pemerintahan dan pusat pelayanan jasa dan termasuk wilayah yang memiliki Kawasan Wilayah Pesisir hasil laut yang memadai.

Kabupaten Pohuwato sebagai wilayah pusat pemerintahan dan pusat pelayanan jasa; termasuk jasa kesehatan, pertanian, perekonomian, perikanan dan lainnya maka sudah sewajarnya dituntut kualitas dari sumber daya aparat desa maupun sumber daya masyarakat yang ada di Kabupaten Pohuwato dalam upaya meningkatkan perekonomian; melalui peningakatan kualitas hidup masyarakat, khususya untuk masyarakat dikawasan wilayah pesisir, harusnya secara mandiri dapat meningkatkan kesejahteraan dan pemeliharaan kesehatan masyarakat, serta penjagaan keamanan dan gerakan aksi tertib hukum untuk masyarakat kawasan pesisir, agar dapat hidup sehat, sejahtera dan peningkatan perekonomian masyarakat tanpa ada penderita stunting dan terhindar dari wabah Covid-19.

Dalam upaya meningkatkan kualitas sumber daya manusia yang ada di Kabupaten Pohuwato, salah satu strategi yang dapat diterapkan adalah dengan melakukan terobosan-terobosan dibidang Aparatur Desa; Bidang edukasi untuk bidang kesehatan, ketertiban, keamanan, perekomian dan kesejahteraan, yakni berupa bentuk pelayanan disegala bidang untuk perbaikan Gizi dalam mencegah peningkatan stunting dan wabah covid-19.

Ada 10 jenis kasus penyakit terbanyak di Kabupaten Pohuwato (Kabupaten Pohuwato dalam angka Tahun 2020, Data Tahun 2019); Jenis kasus penyakit adalah; 1) Commom Cold/Flu Biasa; Jumlah 
kasus: 9 470, 2) Dyspepsia (penyakit tidak nyaman pada perut); Jumlah Kasus: 2983, 3) Important (Primary) Hypertension (peningkatan tekanan darah yang penyebabnya tidak diketahui secara pasti); Jumlah Kasus: 2783. (4) Myalgia (Nyeri Otot); Jumlah Kasus: 1693. (5) Hypertensive Heart Disease (Penyakit Jantung); Jumlah Kasus: 1372. (6) Allergic Contact Dermatitis (peradangan berupa ruam gatal kemerahan pada kulit yang muncul akibat kontak langsung dengan zat tertentu dan mengiritasi kulita); Jumlah Kasus: 1307. (7) Acute pharyngitis (Radang Tenggorokkan); Jumlah Kasus: 1284. (8) Arthritis (Peradangan Sendi); Jumlah Kasus: 806. (9) Diarrhea (Sering Buang Air Besar); Jumlah Kasus: 780. (10) Gastritis (Peradangan Dinding Lambung); Jumlah Kasus: 563.

Sebagai wilayah pusat pemerintahan dan pusat pelayanan jasa, termasuk jasa kesehatan, pertanian, perekonomian, perikanan dan lainnya maka sudah sewajarnya dituntut kualitas dari sumber daya aparat maupun sumber daya masyarakat yang ada di Kabupaten Pohuwato dalam upaya meningkatkan kualitas hidup masyarakat, khususya untuk masyarakat dikawasan wilayah pesisir sehingga secara mandiri dapat meningkatkan kesejahteraan dan pemeliharaan kesehatan masyarakat, serta penjagaan keamanan dan aksi gerakan tertib hukum untuk masyarakat kawasan pesisir, agar dapat hidup sehat, sejahtera dan peningkatan perekonomian masyarakat tanpa ada penderita stunting dan terhindar dari wabah Covid-19, dalam upaya meningkatkan kualitas sumber daya manusia yang ada di Kabupaten Pohuwato, salah satu strategi yang dapat diterapkan adalah dengan melakukan terobosan-terobosan dibidang Aparatur Desa; Bidang edukasi untuk bidang hukum; ketertiban, keamanan, 
perekomian dan kesejahteraan, bidang kesehatan; yakni berupa bentuk pelayanan masyarakat disegala bidang untuk perbaikan Gizi dalam mencegah peningkatan stunting dan wabah covid-19.

Tentunya hal ini di dukung oleh kesigapan pemerintah setempat dan masyarakat, serta kesipan pengolahan sumberdaya alam yang memadai, melalui kepakaran ahli kesehatan, hukum, pendidikan, teknologi, komunikasi dan informasi yang baik. Melatih masyarakat dengan terampil, mengolah potensi alam, laut dan lainnya, hal ini perlu Gerakan aksi bersama masyarakat dalam pengembangan potensi desa, melalui pencegahan dan penyelesaian masalah kemasyarakatan; kesehatan; stunting untuk pemenuhan gizi, melalui gerakan tanggap masyarakat dalam pemenuhan ketersediaan pangan masyarakat, sehingga ini penting untuk Memanfaatkan Pekarangan rumah; lahan tidur dan kebun kosong masyarakat untuk ditanami Barito, sayuran atau Toga.

Berdasarkan permasalahan diatas maka pentingnya untuk mengusulkan kegiatan program KKN Tematik di lembaga Pengabdian masyarakat Universitas Negeri Gorontalo dengan tema; "Pendampingan Pengembangan Potensi Desa Untuk Pemenuhan Gizi Sebagai Pencegahan Stunting Ditengah Pandemik Covid-19 Dalam Ketersediaan Pangan Masyarakat Desa Kawasan Pesisir Kabupaten Pohuwato".

\section{METODE PELAKSANAAN}

Mekanisme pelaksanaan kegiatan KKN Tematik ini meliputi tahapan sebagai berikut :

1. Perekrutan mahasiswa peserta KKN 
2. Melakukan koordinasi dengan Pemerintah Desa/Kecamatan/Daerah Pohuwato

3. Melakukan koordinasi dengan pemerintah desa di Kabupaten Pohuwato

4. Melakukan pembekalan (coaching) terhadap mahasiswa

5. Penyiapan sarana dan perlengkapan

Adapun materi persiapan dan pembekalan yang diberikan kepada mahasiswa mencakup beberapa hal sebagai berikut :

1. Peran dan fungsi mahasiswa dalam program KKN Tematik

2. Penjelasan panduan dan pelaksanaan program KKN Tematik

3. Penjelasan teknik-teknik, BimTek, Pelatihan Ketrampilan dan Pendampingan Pengembangan Potensi Desa Untuk Pemenuhan Gizi Sebagai Pencegahan Stunting Ditengah Pandemik Covid-19 Dalam Ketersediaan Pangan Masyarakat Desa Kawasan Pesisir Kabupaten Pohuwato

Dalam mengatasi persoalan-persoalan sebagaimana yang telah dijelaskan pada sub bab sebelumnya, program KKN (Tematik) Pengabdian pada masyarakat dilaksanakan selama 30 hari, bersama DPL dan 30 orang mahasiswa, diharapkan dapat menjadi solusi alternatif yang ditawarkan untuk meningkatkan kualitas pelayanan terhadap masyarakat dan menciptakan sumber daya manusia terampil dan sehat serta terpenuhi kebutuhan pangannya. Dalam pelaksanaan program pengabdian KKN Tematik ini, terdapat beberapa program pelatihan yang akan dilaksanakan terkait dengan penerapan, sesuai dengan tema; "Pendampingan Pengembangan Potensi Desa Untuk Pemenuhan Gizi Sebagai Pencegahan Stunting Ditengah Pandemik 
Covid-19 Dalam Ketersediaan Pangan Masyarakat Desa Kawasan Pesisir Kabupaten Pohuwato" secara berkelanjutan berupa :

1. Pendidikan dan Pelatihan; Pengembangan Potensi Desa (FGD) Optimalisasi Pelayanan Aparat Desa

Pada kegiatan ini akan dilakukan melalui edukasi pelatihan (FGD/Diklat) Optimalisasi Pelayanan Aparat Desa Kabupaten Pohuwato. Pada pelatihan ini untuk aparat, perangkat dan masyarakat desa di kecamatan Pohuwato, mendapatkan materi Pengembangan Potensi Desanya; Melalui Materi; Kesehatan dan Kepatuhan Hukum oleh Pemerintah Desa dalam pencegahan dan penanganan Stunting dalam situasi New Normal pasca pandemik Covid-19, melalui Tertib Hukum dalam pelayanan kesehatan masyarakat Pohuwato kawasan wilayah pesisir. Pentingnya kegiatan ini; Untuk mendapatkan penanganan kesehatan yang optimal dan ketertiban serta keterlibatan juga kepatuhan program pemerintah dalam kepatuhan protap kesehatan. Masyarakajat mendapatkan informasi terkait bidang pendidikan, kesehatan, hukum, kesejahteraan perekonomian, pengolahan pertanian dan lainnya.

2. Pendampingan pelayanan Gizi untuk kesehatan masyarakat.

Dalam upaya meningkatkan kesehatan masyarakat guna mengoptimalkan Pelayanan Kesehatan masyarakat untuk mencegah Stunting, melalui pemenuhan Gizi ibu hamil dan anak balita dilakukan Pendampingan pelayanan Gizi untuk kesehatan masyarakat Desa Pohuwato. Pendampingan ini melibatkan Posyandu, anak usia prosuktif, ibu hamil dengan usia anak balita; 
0-5 tahun yang ada di Desa Kabupaten Pohuwato. Pada Pendampingan pelayanan Gizi untuk kesehatan masyarakat para , anak usia prosuktif, ibu hamil dengan usia anak balita; 0-5 tahun diberikan pendampingan materi cara pemenuhan gizi yang baik untuk pertumbuhannya dan mendapatkan asupan Gizi Bubur kacang Hijau.

3. BimTek Pencegahan Penularan Wabah Covid-19.

Dalam rangka untuk Pencegahan Penularan Wabah Covid-19; melalui gerakan Pola Hidup Bersih; aksi Cuci tangan, pakai masker dan bagi-bagi masker. Kegiatan ini melibatkan seluruh masyarakat Desa di Kabupaten Pohuwato

4. Pelatihan Pemanfaatan Lahan Tidur pekarangan rumah dan kebun Pelatihan menanam tanaman di halaman dan kebun masyarakat; untuk menanam Barito, sayur dan Toga. Kegiatan ini melibatkan masyarakat yang kelompok gapoktan dan masyarakat yang ingin mengembangkan potensi dibidang pertanian, perekonomian dan peningkatan kesejahteraan hidupnya.

5. Pemanfaatan Pengolahan hasil laut dan pekarangan rumah serta kebun

Pemanfaatan Pengolahan hasil laut dan pekarangan rumah serta kebun, merupakan Program Tambahan; berupa Pengolahan Potensi Pertanian, laut dan tambak untuk kawasan wilayah pesisir, dengan produk; Krepek sayur bayam, Penggaraman Ikan Batu dan Naghet Udang. Manfaat kegiatan ini untuk meningkatkan ekonomi masyarakat melalui usaha-usaha masyarakat produktif mikro kecil dan menengah. Masyarakat juga mendapatkan pelatihan 
pengolahan, pengemasan dan media pemasaran produk-produk usaha kecil masyarakat sehingga diharapkan dapat meningkatkan produktifitas dan penjualan produk tersebut, melalui Pemerintah Desa atau Badan usaha Milik Desa (BUMDES)

Rencana Aksi Program Kegiatan dilaksanakan kepada aparat dan perangkat desa dan Kelompok yang menjadi mitra dalam kegiatan ini merupakan kelompok yang dianggap produktif dan bisa berkembang serta memiliki peran, motivasi dalam memanfaatkan mengambangkan potensi Desa, memperhatikan pendidikan, kesehatan, taat hukum, mau meningkatkan perekonomiannya dan mampu memperhatikan lingkungannya, namun dengan sarana dan prasarana yang belum memadai dan kurangnya pengetahuan sumber daya manusia yang terlibat.

KKN-Tematik; proses pelaksanaan kegiatannya akan dikerjakan oleh mahasiswa yang akan dilakukan, melalui perhitungan Volume kerja, selama jam kerja efektif mahasiswa (JKEM). Setiap mahasiswa harus melakukan pekerjaan sebanyak 144 JKEM selama 2 bulan kegiatan KKN Tematik. Jumlah mahasiswa peserta KKN Tematik, sebanyak 30 orang Mahsiswa. Setiap kegiatan melibatkan beberapa mahasiswa yang bertugas sesuai jadwal kegiatan aksi program, jadi setiap mahasiswa dapat mencapai 288 JKEM dalam 2 bulan. Total volume JKEM adalah 8640. Adapun kegiatan Rencana Aksi program Kerja dapat di rinci sebagai berikut: Agenda kegiatan; FGD: Program Pertama; Pengembangan Potensi Desa untuk Optimalisasi Pelayanan Aparat Desa. Materi; Kesehatan dan Kepatuhan Hukum oleh Pemerintah Desa dalam pencegahan dan penanganan Stunting dalam situasi New Normal pasca pandemik Covid-19, melalui Tertib Hukum 
dalam pelayanan kesehatan masyarakat Pohuwato kawasan wilayah pesisir. Pentingnya kegiatan ini; Untuk mendapatkan penanganan kesehatan yang optimal dan ketertiban serta keterlibatan juga kepatuhan program pemerintah dalam kepatuhan protap kesehatan dan . 2) Pendampingan pelayanan Gizi untuk kesehatan masyarakat. Agenda kegiatan yang kedua; Pendampingan pelayanan Gizi untuk kesehatan masyarakat untuk mengoptimalkan Pelayanan posyandu Desa/kelurahan/kecamatan, sebagai basis pelayanan kesehatan masyarakat; terutama untuk ibu hamil dan anak balita (kegiatannnya dalam bentuk BimTek dan gerakan aski pelayanan kesehatan untuk ibu hamil dan anak balita, serta donor darah). Pentingnya kegiatan; untuk melayani langsung masyarakat; gerakan aksi pelayanan untuk masyarakat dalam menangani Stunting. 3) Program Ketiga; BimTek Pencegahan Penularan Wabah Covid-19; Sosialisasi Pola Hidup Sehat (PHBS); Patuh Protap Kesehatan; Geraka aksi kegiatan ketiga; Cara Cuci tangan dan Pakai masker; Bagi-bagi masker masyarakat pesisir. 4) Porgram Keempat; Pelatihan Pemanfaatan Lahan Tidur pekarangan rumah dan kebun Pelatihan menanam tanaman di halaman dan kebun. Aksi kegiatan keempat ini; dilaksankan bersama DPL, Mahasiswa, Aparat Desa dan Pemateri (Agro Teknologi Pertanian). 5) Program Tambahan; Pemanfaatan Pengolahan hasil laut dan pekarangan rumah serta kebun; Pengolahan Potensi Pertanian, laut dan tambak untuk kawasan wilayah pesisir; Krepek sayur bayam, Penggaraman Ikan Batu dan Naghet Udang. 


\section{HASIL DAN PEMBAHASAN}

Kuliah Kerja Nyata Tematik merupakan perpaduan antara tiga unsur Tri Dharma Perguruan Tinggi, yaitu pendidikan, penelitian dan pengabdian pada masyarakat. Kegiatan ini lebih mengutamakan aktivitas nyata yang dilakukan oleh para mahasiswa, sehingga keberadaannya dalam masyarakat akan bermanfaat bagi masyarakat, khususnya warga masyarakat yang berada di lokasi KKN

Untuk menunjang pencapaian tujuan pendidikan dan sarana KKN ini, kami turut andil dalam wadah kegiatan sosial masyarakat yang diselenggarakan oleh Universitas kami (UNG). Wadah kegiatan terencana dan aplikatif tersebut ialah Kuliah Kerja TEMATIK. KKN merupakan salah satu persyaratan yang harus ditempuh bagi mahasiswa jenjang pendidikan S1 (Universitas Negeri Gorontalo) untuk menyelesaikan masa pendidikannya. Adapun objek (lokasi) KKN yang akan kami selenggarakan di Desa Ayula Kec. Randangan Kab. Pohuwato dengan jumlah kami (Mahasiswa KKN TEMATIK) adalah 30 Orang.

Perencanaan program kami didiskusikan setelah berada di desa Ayula sebagai tawaran program yang akan disesuaikan dengan keadaan yang ada di desa pada tanggal 04 September 2020. Setalah kita melakukan survey penyusunan draf rencana kegiatan kami mahasiswa KKN di desa Ayula melakukan observasi ke masingmasing dusun yang ada. 


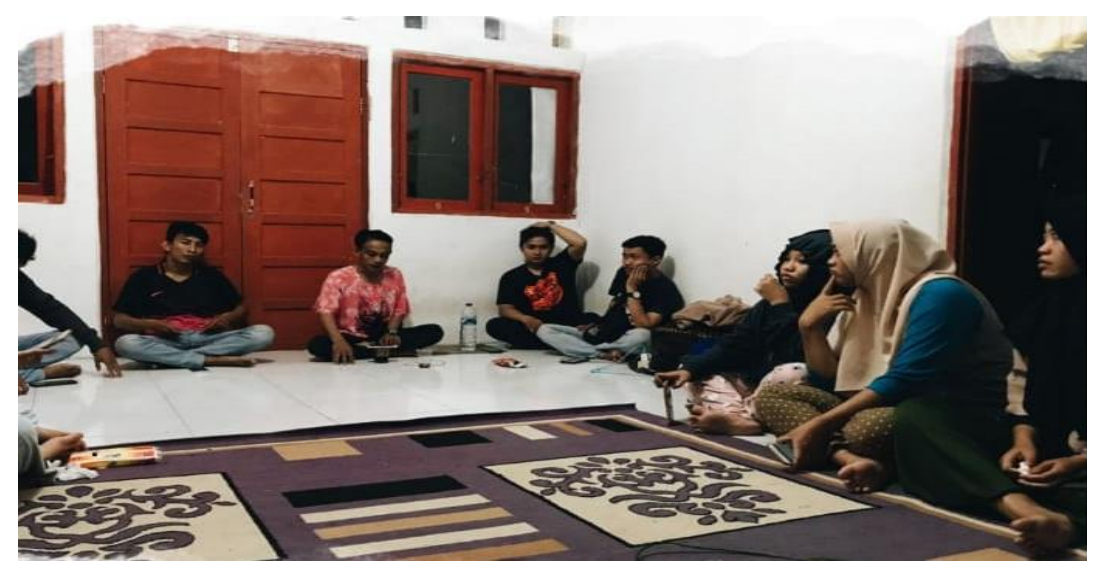

Gambar 1. Rapat Pembentukan Program Kerja

Rapat tersebutkan menghasilkan keputusan bahwa program yang akan dilaksanakan adalah sebagai berikut :

1. Program Inti :

$>$ Penyuluha Pencegahan Stunting dan Penyebaran Covid-19

> Pembuatan Gazebo

2. Program Tambahan :

$>$ Workshop : Daur Ulang Sampah Plastik

$>$ Pekan Olahraga Desa Ayula (PODU) Volly Ball dan Sepak Takraw

Program yang telah dirancang oleh mahasiswa selanjutnya dipaparkan atau disajikan kepada masyarakat pada rapat sosialisasi program kerja ke aparat desa dan BPD untuk mengkoordinasikan program kerja yang akan dilaksanakan.

Dalam melaksanakan rencana program dilaksanakan bersama dengan bantuan masyarakat sekitar yang menginginkan kegiatan ini berhasil. Penerapan hasil perencanaan program berjalan dengan baik, selain mendapatkan dukungan dalam palaksanaan agenda ini kami meminta pada pemerintah setempat Camat, dan Pemkab 
agar kegiatan seperti ini harus dilaksanakan tiap tahunnya agar masyarakat di kelurahan ini bisa menjadi lebih sejahtera.

Implementasi Program Kerja Mahasiswa KKN Tematik UNG tahun 2020 yang terdiri atas program kerja inti dan program kerja tambahan antara lain:

1. Program Kerja Inti

a) Penyuluha Pencegahan Stunting dan Penyebaran Covid-19

Implementasi program kerja inti pada masyarakat di Desa Ayula, tentang "Pencegahan Stunting dan Penyebaran Covid-19" mengarah pada perbaikan Kesehatan yang ada di masyarakat desa yang dilaksanakan oleh mahasiswa KKN Tematik UNG bekerja sama dengan Posyandu Desa pada tanggal 16 September 2020.
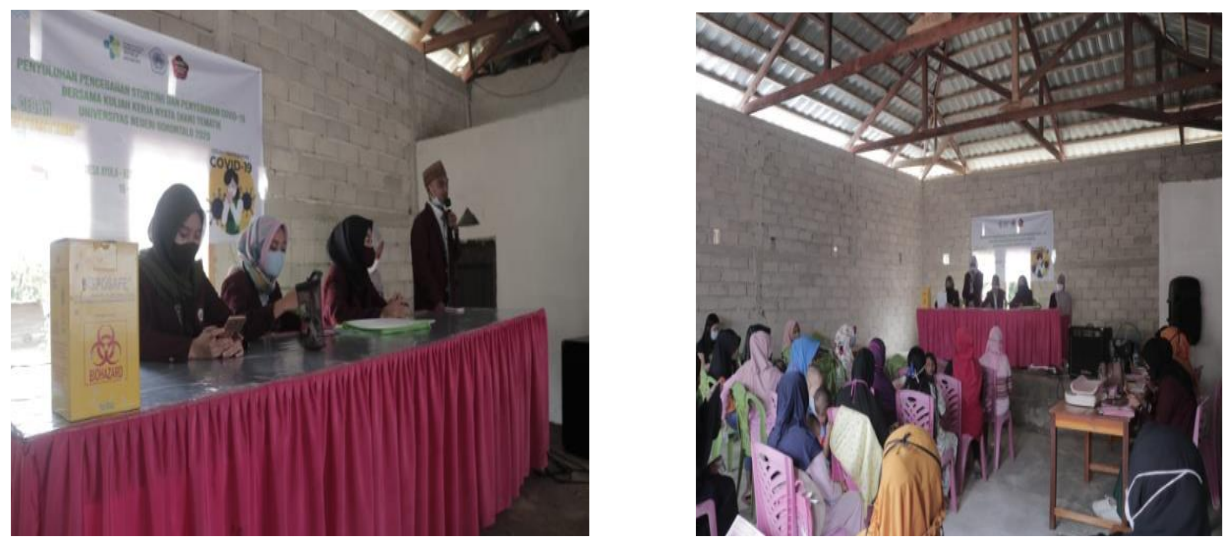

Gambar 2. Pemberian Sambutan Oleh Koordinator Desa 

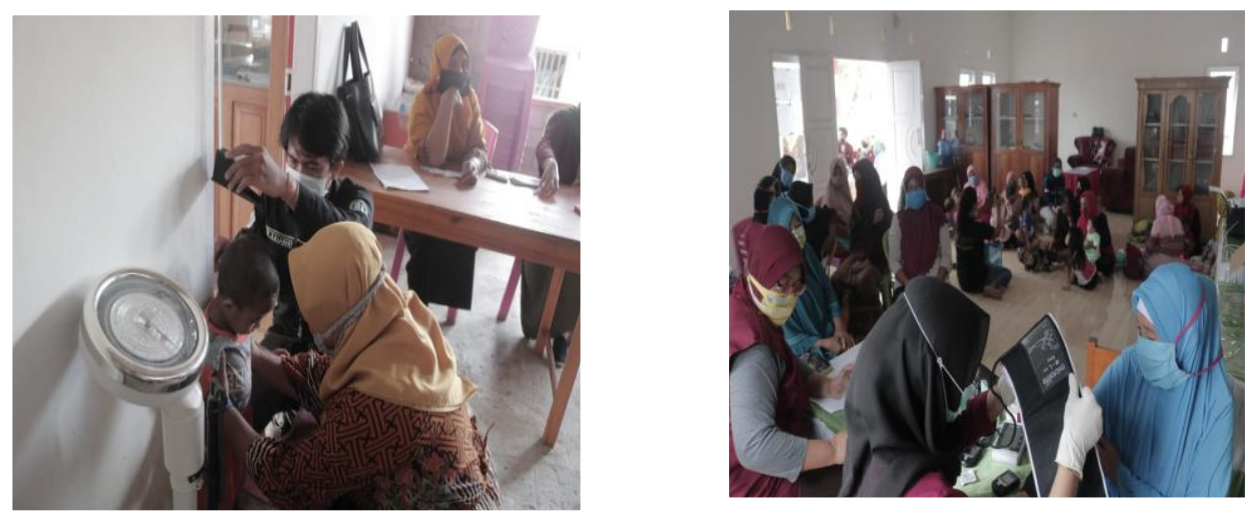

Gambar 3. Pengukuran Tinggi Batita dan. Penyuluhan yang dilakukan oleh posyandu

b) Pembuatan Gajebo

Program inti selanjutnya berhasil membuat gazebo untuk tanaman-tanaman herbal sebagai memenuhan gizi yang dijadikan sebagai asset desa sekaligus sebagai apotik hidup yang dilaksanakan dari tanggal 18 September 2020 sampai peresmian pada tanggal 16 Oktober 2020 yang diresmikan oleh bapak kecamatan Randangan secara simbolis.
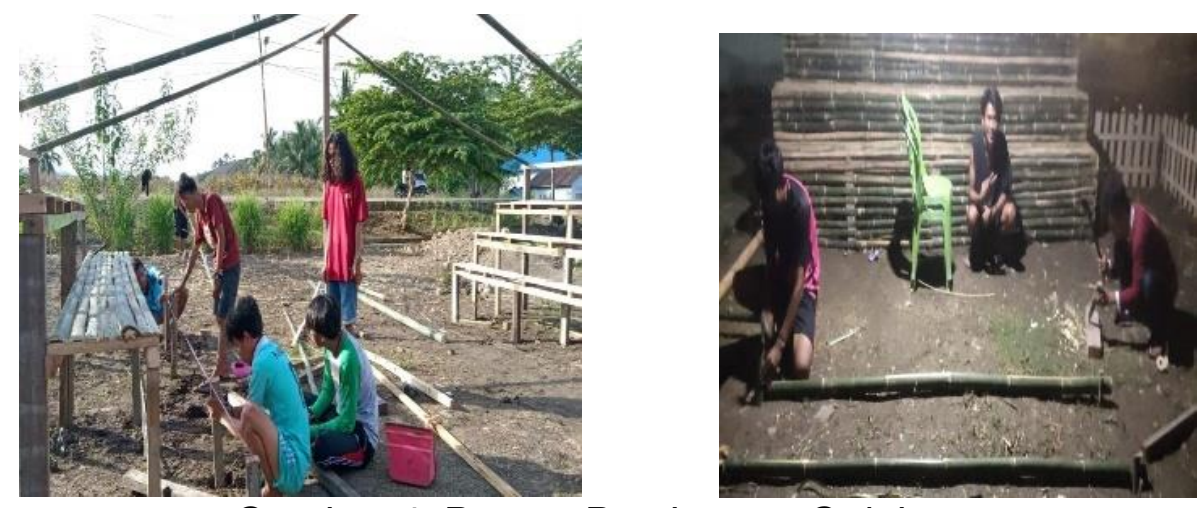

Gambar 4. Proses Pembuatan Gajebo 

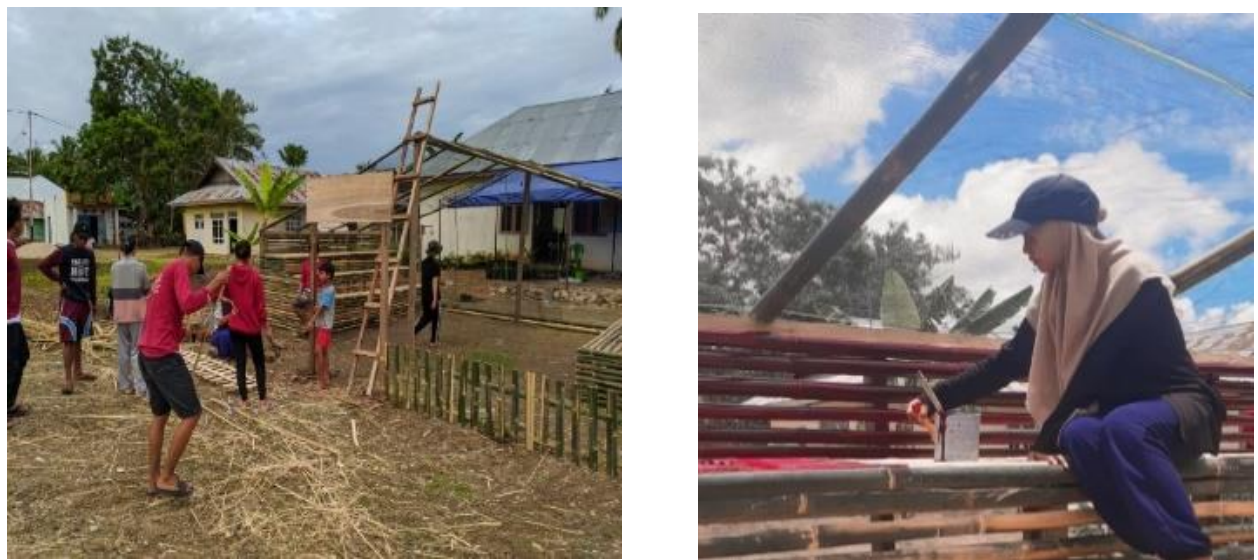

Gambar 5. Proses Pengecetan Gajebo

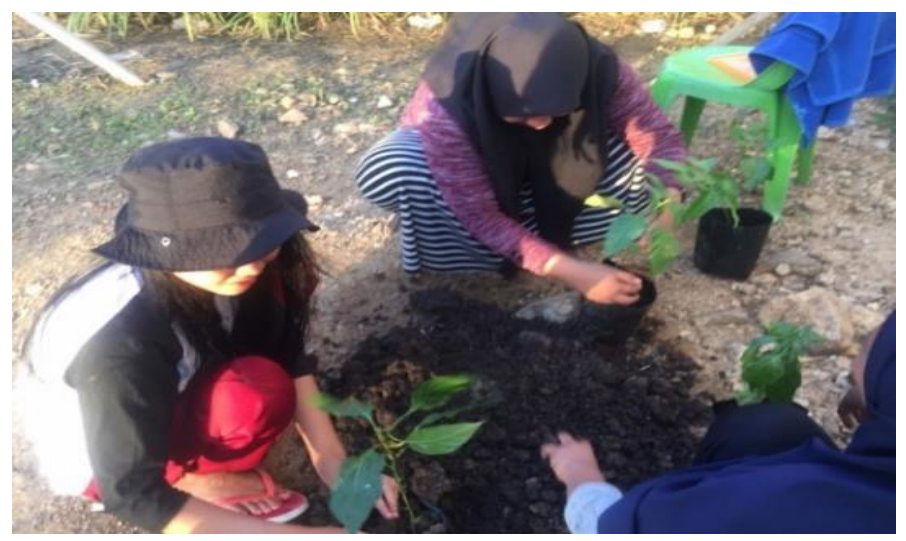

Gambar 6. Proses Penanaman Tanaman Pada Polibag Gajebo

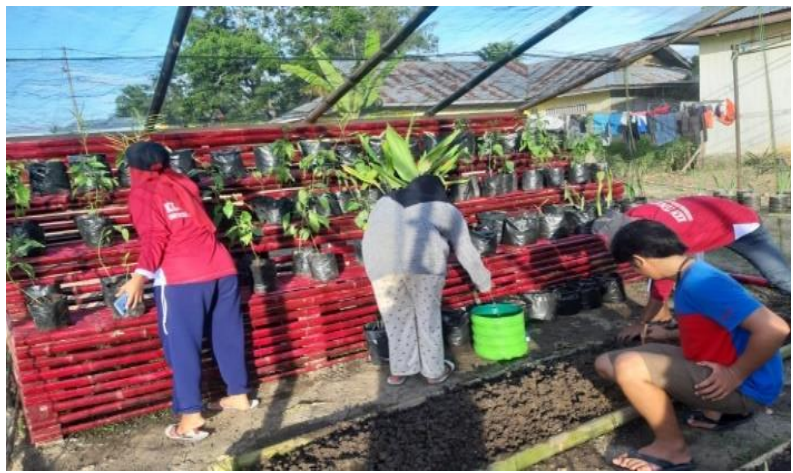

Gambar 7. Proses Penyiraman Tanaman Pada Polibag Gajebo 

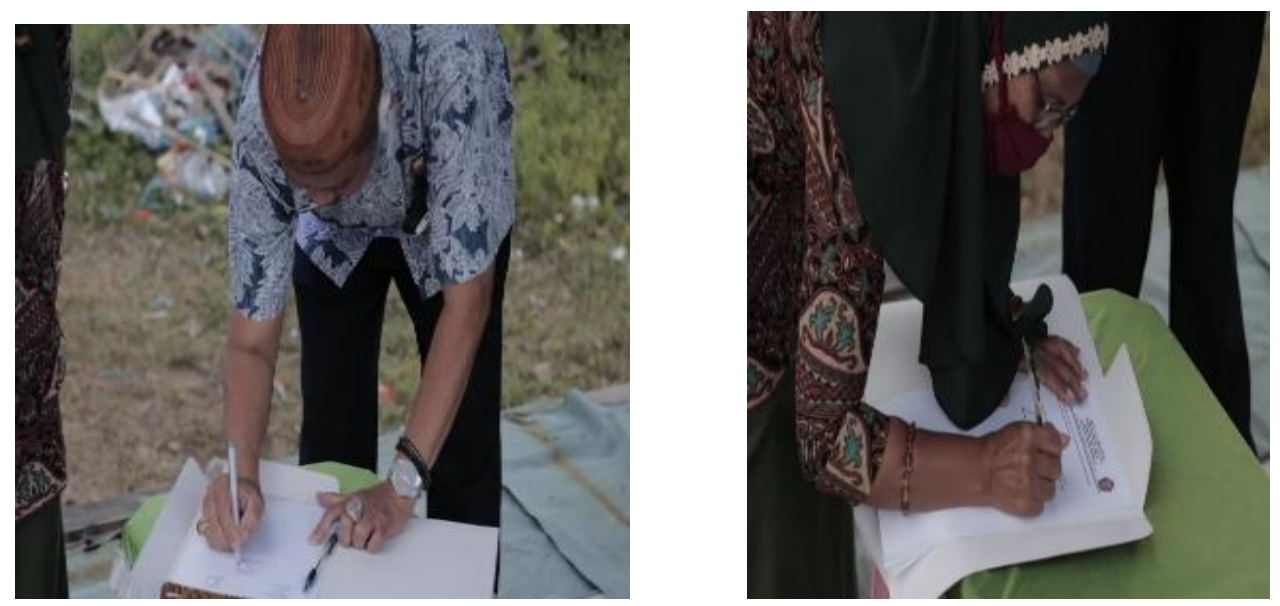

Gambar 8. Proses Penandatangan Surat Penyerahan Gajebo

\section{Program Kerja Tambahan}

a) Workshop Daur Ulang sampah Plastik

Implementasi program kerja tambahan workshop daur ulang sampah plastik ini bertujuan untuk meningktkan pengetahuan masyarakat tentang bgaimana cara mengelolah sampah anorganik menjadi suatu kreasi yang dapat di daur ulang, dan untuk mengajak masyarakat dalam mengelolah sampah menjadi kreasi yang dapat di daura ulang, yang dilaksanakan pada tanggal 28 Sepember 2020.
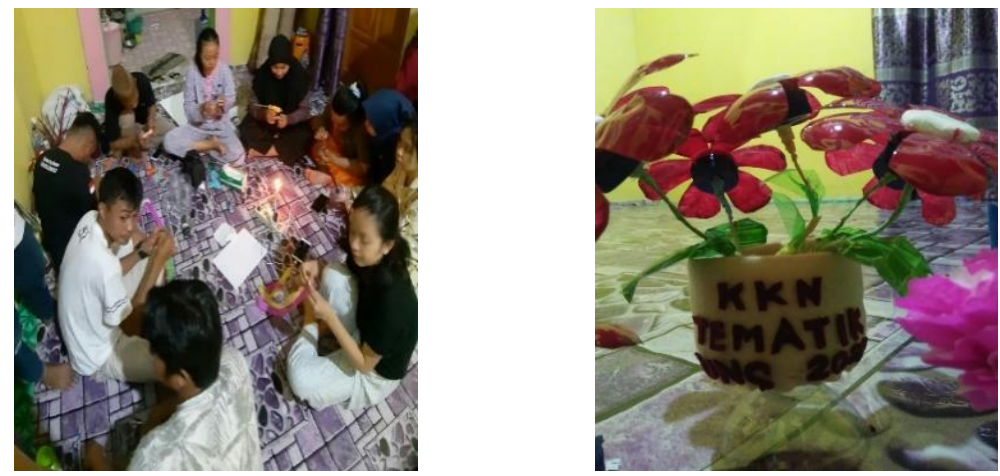

Gambar 9. Proses Pengolahan sampah daur ulang 
c) Pekan Olahraga Desa Ayula (PODU)

Implementasi program kerja tambahan pada masyarakat Desa Ayula bertujuan untuk menjalin tali silaturahmi antara mahasiswa dengan masyarakat maupun antar rema muda dan aparat Desa Ayula. Yang dilaksanakan pada tanggal 10 - 16 Oktober 2020 bertempat di Lapangan Desa Ayula.

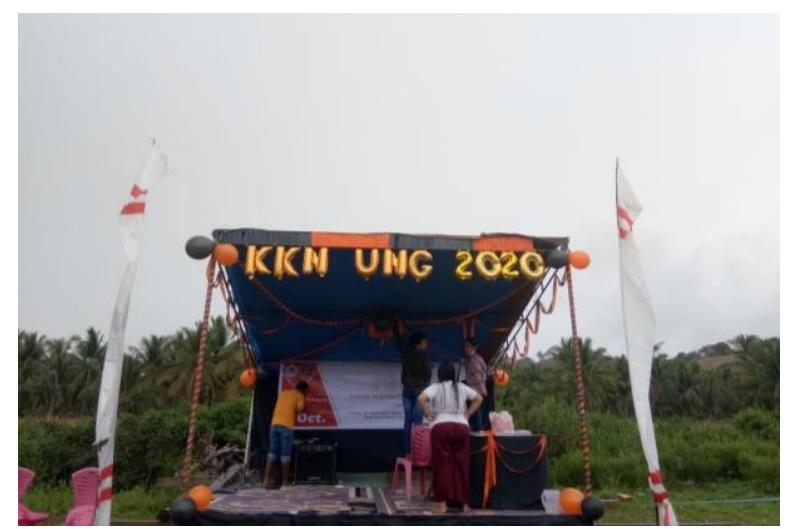

Gambar 10. Proses Pembuatan Panggung Kegiatan

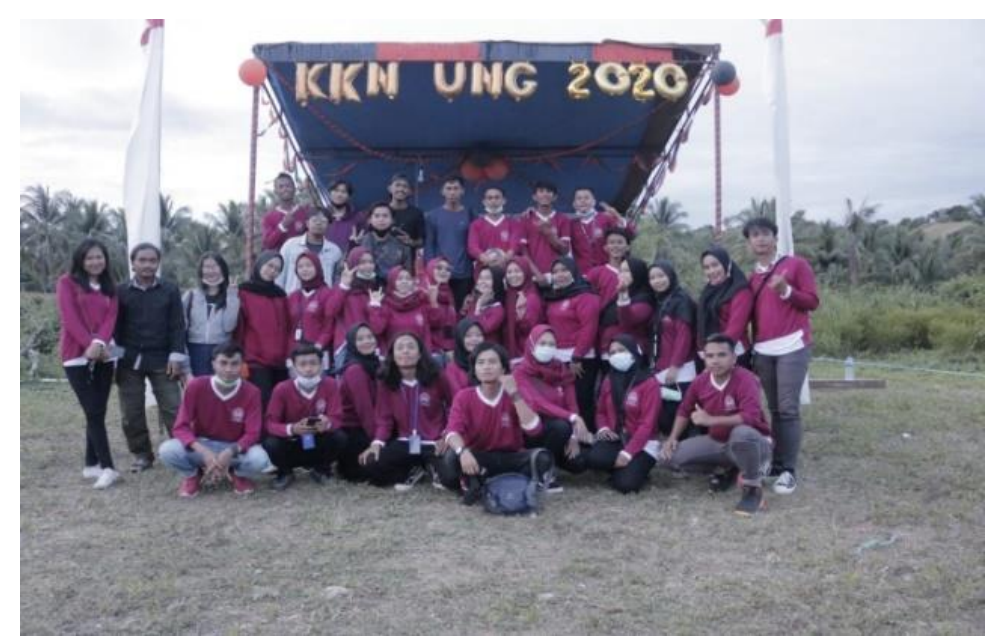

Gambar 11. Peserta KKN sebagai Pelaksana Kegiatan 
1. Program Inti

a. Penyuluhan Stunting dan Covid-19

Sesuai dengan data yang kami dapatkan dari pemerintah desa maupun kader kesehatan dan masyarakat Desa Ayula, untuk kasus stunting itu sendiri sudah tidak ada. Untuk pencegahan stunting itu sendiri kami bekerja sama dengan kader kesehatan Desa Ayula melakukan pendampingan sesuai dengan program kerja. Selain melakukan kerja sama dengan kader kesehatan desa kami juga melakukan kerja sama dengan pihak Puskesmas Motolohu Kecamatan Randangan,khusunya bidang PKPR (Pelayanan Kesehatan Peduli Remaja), pelayanan ini bagian dari pendampingan pencegahan stunting yang dilakukan pada remaja. Karena penyebab terjadinya stunting itu berawal dari kasus pernikahan dini. Maka untuk mencegah hal ini terjadi pihak puskesmas motolohu membentuk posyandu remaja. Dengan tujuan agar remaja tersebut bisa dilakukan pembimbingan dan mendapatkan pelayanan khusus remaja baik dalam bidang kesehatan maupun konseling.

Pencegahan covid-19 itu sendiri di Desa Ayula pemerintah desa dan masyarakat masih mematuhi protokol kesehatan, walaupun beberapa masyarakat yang masih mengabaikan protokol kesehatan. Langkah pencegahan covid-19 di Desa Ayula sangat di dukung penuh oleh Pemerintah Desa terkhusus Kepala Desa Ayula.'

b. Gazebo Tanaman Hijau

Gazebo tanaman hijau ini merupakan asset desa yang kami tinggalkan di Desa Ayula yang bertujuan untuk menjadikan contoh pemanfaatan halaman rumah mereka masing-masing. Untuk di tanami tanaman yang bergizi seperti kacang hijau, bayam, cabai, tomat, kelor, 
dan bawang merah sebagai langkah pemenuhan gizi dan pencegahan stunting. Sedangkan tanaman berupa tanaman herbal seperti kunyit, jahe, kencur, kemangi, dan serai untuk bahan dasar pembuatan jamu, apalagi pada saat pademi covid-19 saat ini sangat cocok untuk di tanami tanaman herbal. Selain untuk kesehatan tanaman tersebut bisa di gunakan untuk bahan masakan di dapur agar masyarakat tidak perlu lagi membeli dan tinggal mengambilnya di pekarangan masingmasing.

2. Program Kerja Tambahan

a. Workshop Daur Ulang Sampah Plastik

Indonesia sekarang ini semakin hari semakin meningkat masalah sampah dan untuk meminimalisir keberadaan sampah diperlukan proses daur ulang terutama non organik. Tujuan dari kami mahasiswa KKN Tematik UNG ingin masyarakat Ayula lebih produktif dengan cara mengolah sampah menjadi suatu kreasi yang dapat di daur ulang seperti botol plastik bekas air mineral dan tas plastik belanjaan. Sasaran kegiatan pengabdian kami untuk masyarakat Ayula ini adalah ibu-ibu rumah tangga, dalam kegiatan ini kami bekerja sama dengan Dinas Lingkungan Hidup Kabupaten Pohuwato dengan masyarakat. Pihak DLH memberikan materi mengenai pengelolaan sampah dan memperlihatkan contoh secara langsung kepada masyarakat ayula hasil dari pengelolaan daur ulang sampah plastik. Kami juga dari mahasiswa KKN Tematik membuat sampel dari botol bekas yang di bentuk menjadi bunga hias. Agar ibu rumah tangga bisa lebih memanfaatkan sampah rumah tangga yang dapat merusak lingkungan. 
b. Kegiatan Pekan Olahraga Desa Ayula (PODU)

Sehubungan dengan dilaksanakannya kegiatan, PODU (Pekan Olahraga Desa Ayula), yang diselenggarakan oleh mahasiswa KKN TEMATIK UNIVERSITAS NEGERI GORONTALO dengan tema "Menjalin Tali Silaturahmi Antara Mahasiswa Dan Masyarakat Desa Ayula Melalui Semangat Olahraga". Guna membangun sportivitas dan kerja sama dalam olahraga bola voli dan takraw yang akan dilakukan oleh masyarakat dan mahasiswa.

\section{SIMPULAN DAN SARAN}

\section{Kesimpulan}

1. Program Kuliah Kerja Nyata (KKN) yang telah terencana dapat berjalan dengan baik meskipun ada kegiatan yang tdak terlaksana sesuai dengan waktu yang telah direncanakan tetapi berubah jadwal karena faktor cuaca dan kegiatan yang tidak terencana dari sasaran program. Tidak hanya itu kendala lain muncul karena kekurangan dana untuk menyelenggarakan kegiatan yang telah direncanakan.

2. Membentuk mahasiswa menjadi lebih dewasa dalam menyikapi permasalahan yang ada dan dapat memahami bagaimana hidup bermasyarakat.

3. Program Kuliah Kerja Nyata (KKN) dapat meningkatkan ilmu dan pengetahuan masyarakat serta dapat menggugah masyarakat terutama dalam bidang Pengembangan Potensi Desa untuk Pemenuhan Gizi sebagai Pencegahan Stunting di Tengah Pandemi Covid-19.

4. Mahasiswa mendapatkan pengalaman dan ilmu kemasyarakatan yang tidak didapatkan di bangku kuliah dan masyarakat dapat 
menyerap ilmuyang dimiliki mahasiswa dalam meningkatkan wawasan mereka untuk kemudian diterapkan dalam kehidupan sehari-hari.

Untuk memberikan masukan seta partisipasi demi kemajuan dalam meningkatkan taraf dan mutu organisasi, saran kepada berbagai pihak yang terkait dalam pelaksanaan KKN ini yang diharapkan dapat memanfaatkan potensi pangan untuk peningkatan gizi masyarakat desa Ayula Kabupaten Pohuwato.

\section{DAFTAR PUSTAKA}

BPS, 2012. Kecamatan Kwandang Dalam angka. BPS Kabupaten Gorontalo Utara (http://pohuwatokab.bps.go.id). DiAkses, Sabtu, 15 Agustus 2020. Jam; 15:20. TOR KKN Tematik 2020.

Gunawan, K. (2011). Manajemen Pemberdayaan Desa dalam Rangka Menekan Laju Urbanisasi. Widyatech Jurnal Sains dan Teknologi, 10(3), 61-72.

Hardijono, R., Maryunani, Yustika, A.E., \& Ananda, C.F., (2014). Economic Independence of The Village Through Institutional Village Enterprises (BUMDes). IOSR Journal of Economics and Finance (IOSR-JEF), 3(2), 21-30.

Mohamad Jafar Hafsah. 2008. Pengentasan Kemiskinan Melalui Pemberdayaan Masyarakat. Bandung: Iris Press (Institute for Religious and Institutional Studies)

Bramasta Dandy Bayu (2020) Mengenal Apa Itu New Normal Di Tengah Pandemi Corona "Diakses tanggal 15 Agustus 2020 . 
Jam;

15:10

dari

http://www.kompas.com/tren/read/2020/05/20/063100865/mengen al-apa-itu-new-normal-di-tengah-pandemi-corona- 